Reprod. Nutr. Dévelop. 1980, 20 (2), 419-441.

\title{
Quelques aspects de l'interaction des hormones stéroïdes avec leurs cellules cibles
}

par E.-E. BAULIEU

Inserm U 33, Faculté de Médecine, Université Paris-Sud, Lab. Hormones, 94270 Bicêtre, France.

Summary. Some aspects of steroid hormone-target cell interaction.

Specific steroid hormone binding proteins in target cells are « receptors ». Five steroid receptors have been described for estrogens, androgens, progesterone, glucocorticosteroids and mineralocorticosteroids, respectively. Their affinity for the natural ligand corresponds to $K_{D}$ approx. $0.1 \mathrm{nM}$. The purified estradiol receptor of the calf uterus appears to be a single-chain protein with a MW of approx. 70000 . Antibodies against this receptor cross-react with other mammalian and avian estradiol receptors.

Steroid hormone-receptor complexes act in the cell nucleus. The mechanism changing gene expression is still unknown. In the chick oviduct system, non-estrogenic antiestrogenic tamoxifen forms nuclear complexes with the receptor, suggesting that receptor translocation from the cytoplasm to the nucleus is not necessarily an indication of hormone agonistic activity, and that the « acceptor » concept may have to be redefined.

Steroid hormone levels vary in target cells. Both homologous and heterologous hormones may control the concentration of a given steroid receptor, either positively or negatively. Receptor variations during the estrous and menstrual cycles appear to be correlated with changes of steroid hormone levels in the plasma. Steroid receptor concentrations in target cells also follow ontogenetic patterns reflecting genetic variations and pathological changes, i.e. in cancer cells. The receptor must be present for steroid hormone response, and it appears that its concentration is directly implicated in the extent of the effect obtained. Thus, the level of nuclear hormone receptor complexes and its persistence are important factors.

A physiological pharmacology of natural and synthetic hormones and antihormones can be based on binding properties, plurality and changes in receptor concentration. Binding parameters per se do nof indicate whether a binding steroid or analog will be agonist or antagonist. Besides binding affinity, the metabolism of a given hormone, and therefore its availability at the target cell level, are important criteria in determining the response level. Binding to steroid binding plasma proteins must also be considered.

Besides the already « classical 》 steroid-intracellular receptor system acting at the nuclear level, work in Xenopus leavis oocytes has suggested that steroids may act at the surface membrane level, reinitiating meiosis. The significance of this finding is discussed with reference to the possible effects of steroid hormones on somatic cells at the membrane level. It remains to be established if a steroid hormone can have several molecular action mechanisms in a single target cell. 
Ce texte résume les observations qui ont conduit à la découverte des récepteurs des hormones stéroïdes et il indique à quel niveau de compréhension on est arrivé (l, II). Nous détaillons ensuite les principales notions physiologiques et pharmacologiques permettant d'étudier la « réceptivité » hormonale. II s'agit en particulier de la régulation de la concentration des récepteurs (III), de la pluralité des liaisons hormonales et de la multiplicité cellulaire des récepteurs (IV). Puis nous résumons des recherches récentes sur la méiose de l'ovocyte de Xenopus laevis, qui permettent d'étudier l'effet de la progestérone dans un cas qui, contrairement au système des récepteurs intracellulaires classiques, implique une interaction du stéroïde au niveau de la surface de la cellule; la portée plus générale de cette observation est discutée ensuite (V).

\section{I. - Les « récepteurs » sont des protéines liant spécifiquement les hormones stéroïdes dans leurs cellules cibles.}

C'est le récepteur de l'œstradiol qui a inauguré le domaine des récepteurs des hormones stéroïdes, et de fait il a été le premier de tous les récepteurs à être caractérisé, bien avant ceux des autres hormones (en particulier polypeptidiques) et des neuromédiateurs. Le mot et le concept du récepteur avaient été initialement définis et utilisés par les pharmacologistes, et malgré la préscience de Langley il y a 100 ans et l'orientation chimique d'Ehrlich au début du siècle, ils en étaient restés à des études purement phénoménologiques. En fait, ce sont des endocrinologisfes-biochimistes qui ont pour la première fois mis en évidence des interactions physico-chimiques signifiantes, et très précisément en utilisant l'œstradiol tritié de haute activité spécifique.

L'œstrogène naturel, l'œstradiol, est spécifiquement concentré ef refenu dans ses organes cibles (1). Cette observation fondamentale a pu être expliquée en termes biochimiques par les propriétés intrinsèques d'une protéine intracellulaire solubilisée facilement à partir des cellules cibles. En effet, les études de liaison in vitro démontrèrent une spécificité stricte de signification biologique évidente $(2,3)$. Deux techniques furent utilisées : 1) L'ultracentrifugation en gradient de saccharose (ou de glycérol) qui permit, après incubation in vitro avec l'hormone radioactive, d'isoler des complexes radioactifs « $8 \mathrm{~S}$ » en milieu de faible force ionique (4) ; 2) L'utilisation des adsorbants et avant tout le charbon actif (mélange charbon-dextran) qui, en rationalisant les résultats selon le principe de la dissociation différentielle (5), permirent des études quantitatives (2). Les récepteurs des hormones stéroïdes ont une affinité très élevée

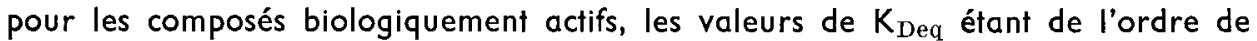
$0,1 \mathrm{nM}$, ce qui est parfaitement adapté aux concentrations circulantes des hormones correspondantes. Les vitesses de dissociation très lentes des complexes hormonerécepteurs $(6,7)$ sont compatibles avec la rétention prolongée du stéroïde hormonal observée par les expériences in vivo (1).

Sur la base de cette propriété, et bien que seuls des résultats indirects indiquent actuellement que ces protéines liantes intracellulaires sont véritablement impliquées dans la médiation de l'activité hormonale (8), elles furent appelées « récepteurs ». En tout cas ces protéines sont certainement différentes d'autres protéines liant les stéroïdes que l'on trouve dans le plasma, dans les testicules, dans le foie, dans la prostate, etc..., dont les propriétés de liaison ne rendent pas compte de l'activité biologique des ligands (8). Par exemple, la protéine plasmatique (Sex Steroid Binding Plasma Protein) 
(SBP) (9) qui lie l'œstradiol avec une affinité élevée, lie également la testostérone, et même plus étroitement, ce qui contraste avec le récepteur de l'œstradiol dont l'affinité pour les androgènes est très faible. Réciproquement, le diéthylstilbœstrol (DES), un œstrogène de synthèse actif mais non stéroïde, se lie au récepteur de l'œstradiol et à peine à la SBP ou à l' $\alpha$-fœetoprotéine chez le rat $(\alpha-F P)(10,10$ bis). Il s'agit bien de protéines distinctes, et les observations récentes avec des anticorps anti-récepteur de l'œstradiol (11), anti- $\alpha$-fœtoprotéine (12) et anti-SBP (13) confirment la singularité du récepteur de l'œstradiol. Elles montrent de plus que le récepteur de l'œstradiol des différents organes de différents mammifères ont des déterminants antigéniques communs avec le récepteur de l'utérus de veau (14). Très récemment (15) nous avons même observé l'interaction d'anticorps anti-récepteur de l'œstradiol de l'utérus de veau avec le récepleur nucléaire de l'œstradiol de l'oviducte de poule : comme si le récepteur de l'œstradiol était remarquablement préservé au cours de l'évolution, comme par exemple une enzyme importante, la RNA-polymérase $B$.

Un récepteur a été décrit pour chacune des 5 hormones stéroïdes physiologique ment bien définie. En plus du récepteur de l'œstradiol, ce sont le récepteur des androgènes, d'abord décrit dans la prostate ventrale de rat (16-18) ; le récepteur de la progestérone, d'abord observé dans l'utérus de cobaye (19) et dans l'oviducte aviaire (20) ; le récepteur des glucocorticostéroïdes, découvert dans les cellules de thymus (21) et le récepteur des minéralocorticostéroïdes, détecté dans la vessie de crapaud (22) et étudié dans le rein de rat (23). Dans l'ensemble les affinités correspondent dans chaque cas aux activités biologiques de la plupart des agonistes. La concentration des récepteurs dans les cellules-cibles est de l'ordre de 10000 par cellule, avec des valeurs variant entre $10^{3}$ et $10^{5}$. Certaines propriétés, en particulier de liaison, indiquent une grande similitude entre les récepteurs des différents organes et des diverses espèces animales, encore que, contrairement au cas des récepteurs de l'œstradiol, les récepteurs de la progestérone semblent différer chez les mammifères et les aviaires.

Avec chaque hormone naturelle, les expériences de liaison ont essentiellement indiqué une seule catégorie de site d'affinité élevée $\left(K_{\mathrm{Deq}} \sim 0,1 \mathrm{nM}\right)$ - et aucun élément n'a démontré un effet coopératif au niveau de la liaison. De plus, jusqu'à présent, les travaux de purification, les recherches immunologiques ou les études de liaison n'ont pas indiqué que les récepteurs soient hétérogènes. En fait, les fréquentes références à l'« hétérogénéité » des récepteurs semblent correspondre surtout à des différences de taille ou d'extractibilité attribuables à des circonstances expérimentales particulières (agrégation, protéolyse). La signification du récepteur nucléaire «insoluble » (24), ef la raison pour laquelle une fraction des sites de la progestérone n'est apparemment pas transférée dans le noyau (25) restent assez obscures. Il est cependanł possible que les récepteurs eux-mêmes pourraient interagir avec plusieurs structures différentes dans la même cellule. De plus dans des cellules de différenciation distincte, le récepteur se lierait sélectivement avec des « accepteurs» et/ou des « effecteurs》 différents, ce qui serait une base logique pour comprendre que la même hormone puisse donner lieu d̀ différents effets, bien qu'interagissant avec le même récepteur dans tous les cas.

La structure des récepteurs des hormones stéroïdes n'est pas connue, en dépit des progrès importants des techniques de chromatographie d'affinité (26-29). Nous savons qu'il s'agif de protéines, de poids moléculaire $\sim 70000$ dans le cas du récepteur de 
l'œstradiol d'utérus de veau, si l'on considère une unité de liaison. Une protéolyse partielle peut dans tous les cas découper une portion de la protéine sans pour autant changer les caractéristiques de liaison hormonale (30-32). Les anticorps produits à partir du récepteur extrait du cytosol (11) ou des noyaux (14) sont très semblables. La purification à grande échelle (des $\mathrm{mg}$ ) des récepteurs est une des exigences de la recherche dans ce domaine.

\section{II. - Les complexes récepteur-hormone stéroïde agissent dans le noyau des cellules cibles.}

Les complexes des hormones stéroïdes et de leurs récepteurs s'accumulent dans le noyau des cellules cibles où, en toute probabilité, ils déclenchent les principales réponses en affectant la transcription des gènes.

On sait depuis longtemps que la plupart des réponses aux hormones stéroïdes impliquent des changements de la synthèse des protéines ef des acides ribonucléiques (33). Récemment, l'accumulation de m-RNA(s) spécifique(s) a été démontrée dans les cas où la synthèse de la (ou des) protéine(s) correspondante(s) étail augmentée $(34,35)$. L'implication des récepteurs dans ces effets découle de plusieurs séries d'observations.

En premier lieu, dans de nombreux systèmes, le récepteur est principalement cyłoplasmique en l'absence d'hormone et il transfère dans le noyau avec le stéroïde (36, 37). Ce changement de la distribution subcellulaire des récepteurs semble refléter ce que l'on a appelé l'« activation » du récepteur, qui peut être définie expérimentalement comme un accroissement, après liaison du stéroïde, de l'affinité du récepteur pour des polyanions dont le DNA $(38,39) *$. Les études autoradiographiques ont montré que les stéroïdes se localisent préférentiellement au niveau des noyaux dans les cellules cibles (40), ef très récemment, on a observé une association sélective du récepteur (de l'œestradiol) avec des éléments chromatiniens solubilisés de l'oviducte de poule $(41,42)$. Cependant on verra plus loin que le transfert nucléaire du récepteur après liaison d'un ligand ne mène pas nécessairement à la réponse hormonale. Ainsi insistons-nous sur le fait qu'il faut distinguer entre les sites accepteurs et effecteurs du récepteur comme il est indiqué sur la figure 1. De plus le transfert du récepteur n'est probablement pas toujours nécessaire pour la réponse hormonale, en particulier quand le récepteur est déjà localisé dans le noyau en l'absence d'hormones $(43,44)$ ou quand il a été transloqué préalablement par une anti-hormone (voir chap. IV). Nous pensons donc que la présence dans le noyau de complexes hormone-récepteur actifs déclenche des réponses hormonales au niveau de sifes effecteurs. Aussi insistons-nous sur la structure du ligand favorisant la conformation active du récepteur, plus que sur la localisation initiale du récepteur (libre) dans le cytoplasme ou dans le noyau. Cette proposition a pour conséquence de diminuer l'importance de la redistribution du récepteur, bien que dans de nombreux systèmes celle-ci soit une conséquence (utile) de la formation des complexes hormone-récepteur actifs.

* Le destin ultérieur des complexes hormone-récepteur dans les cellules après l'étape nucléaire et le déclenchement de la réponse, n'est pas connue. "Désactivation " ou " altération par protéolyse " sont parmi les possibilités qui ont été proposées. 
D'autre part, l'incorporation accrue de précurseurs radioactifs dans l'ARN a été observée après exposition des noyaux de cellules cibles à des extraits cytoplasmiques contenant des complexes hormone-récepteur (45). Cette constatation a permis de suggérer la participation directe du récepteur à l'effet, puisque l'hormone à elle seule n'est pas active sur le noyau ne contenant pas de récepteur. Ces observations, comme les connaissances actuelles sur les processus de transcription sur les cellules eucaryotes, restent très primitives. Jusqu'à présent il n'y a pas de démonstration décisive que l'addition d'un complexe hormone-récepteur à une préparation chromatinienne en modifie la transcription, en particulier en ce qui concerne la synthèse d'un ARN messager spécifique (46). En fait toutes les réponses provoquées par les hormones stéroïdes sont mal


FIG. 1. - Phénoménologie du récepteur $(R)$ des hormones stéroides $(H)$.

$r$ est le site de liaison de $H$, indiquant qu'il s'agit d'un site "récepteur », " reveveur ", " régulateur ». $r$ est spécifique sur le plan « qualitatif » hormonal, lie réversiblement l'hormone et constitue la dernière interaction de l'hormone avec la machine cellulaire avant que se déclenche la réponse (ce qui ne serait pas le cas si $r$ était le site de liaison d'une protéine de transport intracellulaire) : H-R constitue l' " interaction efficace ultime » de l'hormone dans la cellule.

Un mécanisme de transduction ou de couplage prend place entre $r$ et le (s) site (s) a et/ou e.

La réponse prend place au niveau d'une structure effectrice $E$ de la machine cellulaire. Le récepteur a un site e (pour " effecteur », " exécutif ») qui interagit avec E, soił qu'il s'agisse de catalyser l'action chimique ( $R$ est alors un enzyme allostérique), ou simplement de liaison à $E$ (et dans ce cas les sites e et a peuvent être confondus). De toute façon, il existe une spécificité necessaire pour expliquer que les effets différents puissent être déclenchés par différents récepteurs d'hormones stéroïdes dans la même cellule. A est une autre partie de la machine cellulaire appelée Accepteur avec lequel le site $a$ du récepteur peut interagir. A correspond opérationnellement à l'endroit auquel se lie le complexe hormone-récepleur, avec une affinité inconnue et des sites qui sont peut-être en nombre très élevé et ne sont pas nécessairement tous identiques (114). Il est possible mais pas démontré, qu'un petit nombre de sites de haute affinité soit caché par un nombre plus grand de sites d'affinité plus faible (50). On sait que les stéroïdes peuvent provoquer la synthèse accrue de nombreuses protéines (comme dans le cas de la croissance cellulaire provoquée par les hormones sexuelles) ou seulement de quelques-unes (comme dans le cas de l'aldostérone agissant sur le transport du sodium) : aucune différence n'a été observée au niveau du système des récepteurs. En d'autres termes, on ne sait pas encore quelle est la relation reliant l'état du récepteur dans le noyau ef le type de la réponse hormonale. A et $E$ peuvent ou non être une même structure, partiellement ou totalement, et la même chose est possible pour a ou e.

L'effet provoqué par la liaison d'une anti-hormone au site $r$ peut provoquer des changements de conformation ou stabiliser une autre conformation du récepteur, modifiant par conséquent le fonctionnement des sites a et/ou e, et abolissant ainsi l'effet hormonal.

Nous n'avons pas indiqué sur cette figure la possibilité qu'il existe un autre site sur le récepteur pour des ligands antagonistes $(116,95)$, ni des sites qui pourraient être impliqués dans l'inactivation des récepteurs (comme on l'a démontré avec la progestérone (5).

Les faits obtenus par les chercheurs de divers laboratoires $(31,34,57,117-120)$ sont compatibles dans l'ensemble avec le schéma présenté. 
comprises sur le plan de leur mécanisme. Par exemple l'inhibition de la synthèse des protéines n'a pas d'effet sur l'augmentation initiale de l'ARN viral par les glucocorticostéroīdes dans les cellules GR (47) alors qu'au contraire l'augmentation provoquée par l'cestradiol des messagers de la conalbumine ef de l'ovalbumine y semble sensible (48). De plus, la cinétique d'induction de l'ovalbumine et de la conalbumine ainsi que de leurs ARNs messagers après œstradiol et progestérone $(35,49)$ est difficile à expliquer dans leur diversité et beaucoup de travail reste à faire pour la comprendre.

\section{III. - La concentration des hormones stéroïdes varie dans les cellules cibles, ce qui peut jouer un rôle essentiel dans la réceptivité hormonale.}

La concentration des hormones stéroïdes peut varier sous diverses influences hormonales, développementales, génétiques, pathologiques ou pharmacologiques. Même si la structure et le mécanisme d'action des récepteurs ne sont pas encore connus en détail, l'étude de ces variations de concentralion est importante pour comprendre le déterminisme des processus hormono-dépendant. L'endocrinologie des récepteurs complète maintenant celle des hormones.

Les variations qui dépendent des hormones ont éfé décrites les premières, et l'étude des variations du récepleur de la progestérone de l'utérus pendant le cycle œstral conduit à découvrir un double mécanisme régulateur (50). Le contrôle positif s'observe à l'évidence quand on mesure l'augmentation de la synthèse des récepteurs de la progestérone par l'œstradiol, qu'il s'agisse du pic préovulatoire physiologique ou d'une administration pharmacologique d'œstrogènes $(19,20)$ : le classique effet de facilitation (priming) des œstrogènes sur l'action de la progestérone semble ainsi expliqué. Ce contrôle positif de la concentration d'un récepteur est plus difficile à analyser quand c'est l'hormone elle-même qui accroît la concentration de son propre récepteur, ce qui est le cas pour les œstrogènes ef les androgènes. D'autre part ef inversement, la progestérone exerce un effeł négatif sur son récepteur, en accélérant la décroissance de sa capacilé de liaison (50). Cette inactivation n'est pas analysée jusqu'à présent sur le plan moléculaire, et elle semble se produire au moins en partie dans le noyau. La « down-regulation » décrivant l'effet de plusieurs hormones polypeptidiques sur leur récepteur (51) est très semblable à ce qui a été observé avec le récepteur de la progestérone, et elle explique au moins en partie la désensibilisation de la cellule cible.

Les contrôles positif et négatif de la concentration des récepteurs varient selon les types cellulaires, leur différenciation, et les différentes constantes hormonales, métaboliques ef fonctionnelles. La complexité est évidente quand on étudie les interactions entre l'œstradiol et la progestérone. En effet, en plus des faits cités plus haut, on a pu démontrer que la progestérone peut accroître le récepteur de l'œstradiol directement ou au contraire diminuer son augmentation provoquée par l'œstradiol (52-54), etc... Les variations observées au cours du cycle menstruel normal chez la femme dans l'endomètre constituent un ensemble remarquable $(55$, fig. 2$)$. Les changements de concentration et de distribution subcellulaire observés peuvent essentiellement s'expliquer en suivant les conclusions tirées des observations faites sur les modèles animaux de laboratoire. Incidemment notons que la concentration des récepteurs de l'œstradiol 
ef leur contrôle ne sont pas identiques dans l'endomètre et le myomètre, pourtant juxtaposés dans le même organe $(52,56,57)$.
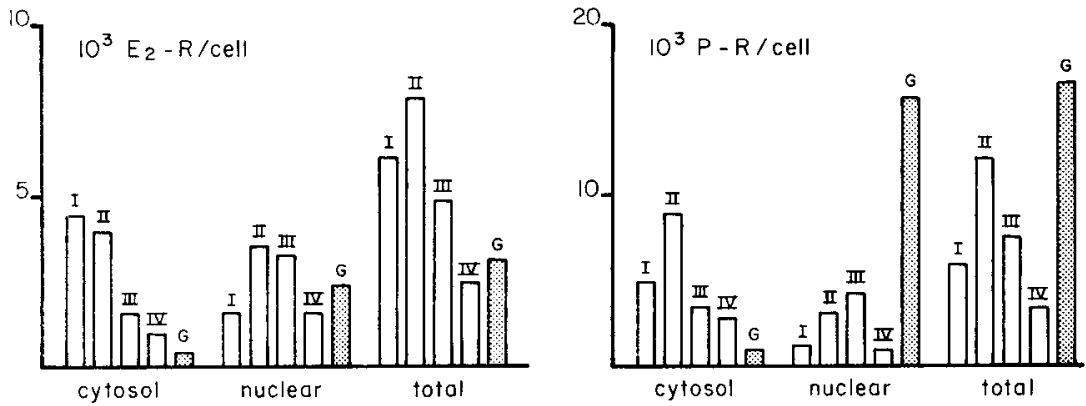

FIG. 2. - Le récepteur de l'œstradiol $\left(E_{2} R\right)$ et le récepteur de la progestérone (P-R) dans le cytoplasme (cytosol) et les noyaux (nuclear) des cellules de l'endomètre durant le cycle menstruel chez les femmes normales. Quałre périodes ont été définies ; 1 : commence au jour des règles et s'arrête 5 jours avant le pic de LH ; II : commence 5 jours avant le pic de LH et dure jusqu'à celui-ci ; III : s'étend du pic de LH à 5 jours après ; IV : couvre les jours suivants jusqu'aux règles. De plus des résultats $(G)$ ont été obtenus sur la décidua de produits d'avortements à 6-8 semaines. Les valeurs indiquées « total » sont la somme des nombres obtenus pour le cytosol et la fraction nucléaire, et les résultats ont été calculés en milliers de sites de liaison par cellule.

Les changements de concentration des récepteurs surviennent aussi au cours du développement. Par exemple, les changements de réceptivité aux androgènes des bourgeons prostatiques (58) ou mammaires (69) ne semblent pas sous le contrôle des androgènes eux-mêmes. Dans d'autres cas, les modifications au cours du développement dépendent au contraire, de la concentration hormonale comme par exemple l'accroissement de la sensibilité aux œstrogènes (60) et l'augmentation de la concentration des récepteurs correspondants (61) au niveau de l'utérus de rat, qui coïncident avec une augmentation des œstrogènes plasmatiques vers le dixième jour de vie. Il est d'ailleurs intéressant que les changements de concentration des récepteurs de l'œstradiol dans d'autres organes, tels l'hypothalamus ef l'hypophyse, ne suivent pas le même développement temporel (62).

Des causes génétiques peuvent être à l'origine d'une modification de la concentration des récepteurs : le cas le plus net est réalisé chez les mutants « $\mathrm{tfm}$ » qui chez l'homme entraînent le syndrome du « testicule féminisant », et, comme chez plusieurs animaux, est caractérisé par un phénotype féminin, un taux de testostérone normal, et une extrême diminution de la concentration des sites du récepteur des androgènes (63). On peutégalement obtenir in vitro des cellules lymphoïdes caractérisées par l'absence de récepteur et de réponse (killing effect) aux glucocorticostéroïdes (64). On a même pu, sur des cellules de ce type, mettre en évidence un véritable dosage génétique qui a permis de corréler la sensibilité hormonale ef la concentration des récepleurs, plus de ces derniers permettant à une concentration hormonale plus faible d'être efficace (65).

Les variations de concentration des récepteurs des stéroïdes sont importantes cliniquement. Au cours des cancers du sein $(66,67)$ et de l'endomètre $(68)$, on observe des 
taux de récepteurs de l'œstradiol et de la progestérone très variables selon les cas, ef en particulier sans rapport avec les particularités histologiques et éventuellement étiologiques de ces cancers. On a proposé une corrélation entre la réponse au traitement endocrinien et la présence (c'est-à-dire un niveau de concentration minimum) du récepteur de l'œstradiol (66), bien que l'on conçoive que l'hétérogénéité cellulaire fréquente rende assez difficiles l'interprétation des nombres de récepteurs ef le pronostic. Cependant on a démontré de façon claire qu'en absence de récepteur ou tout au moins en dessous d'un seuil très faible, les tumeurs ne sont pas sensibles aux hormones.

II faut remarquer que, quelle que soit la raison des changements de la concentration des récepteurs, la spécificité et l'affinité de liaison restent identiques. Ce système de régulation opère seulement au plan quantitatif. Les récepteurs n'expliquent pas fous les effets observés, même au seul plan de l'importance de la réponse considérée. Par exemple, dans l'oviducte de poule, la demi-augmentation maximale de la synthèse de l'ovalbumine demande deux fois plus d'hormone qu'il en faut pour obtenir la demiélévation maximum de la conalbumine, et ce, que l'œstradiol ou la progestérone soit en jeu (69). D'autre part, selon la dose, l'œstradiol et la progesiérone qui sont séparément agonistes, peuvent être éventuellement synergiques ou antagonistes pour le même paramètre, tel que la synthèse de l'ovalbumine, et selon les circonstances, une même dose de progestérone peut être simultanément synergique de l'œstradiol pour la synthèse des protéines spécifiques et anti-œstrogène en ce qui concerne l'augmentation de la DNA polymérase (70). On peut imaginer de nombreux mécanismes pour expliquer ces résulfats. Aucun n'est formellement démontré. On a parlé en particulier de l'engagement nécessaire d'un nombre différent de molécules du même récepteur pour moduler le fonctionnement de différents gènes, ou de l'existence d'étapes intermédiaires encore mal identifiées entre le récepteur et les réponses que l'on mesure (voir les discussions sur « Kip » (key intermediary protein (71) ou sur la « translocation du récepteur ») (49)).

En conclusion, la présence du récepteur est nécessaire à l'action hormonale, et sa concentration est impliquée dans l'importance du (ou des) effet(s) obtenu(s). La concentration des complexes hormone-récepteur au niveau nucléaire et leur persistance sont l'une et l'autre importantes à cet égard (72-74). Cependant, il faut prendre aussi en considération les paramètres stéréo-chimiques et cinétiques des interactions que l'on peut mettre en évidence par des éfudes de liaison (voir plus loin), et des éléments «post-récepteurs » de la machine cellulaire qui nécessairement jouent un rôle dans l'établissement de la réponse (75).

\section{IV. - Pharmacologie physiologique des hormones naturelles et de synthèse et des anti-hormones, basée sur les propriétés de liaison, la pluralité et les changements de concentration des récepteurs.}

\section{Propriétés de liaison ef pluralité des récepteurs.}

Une hormone donnée peut interagir avec différents récepteurs. Ceci fut initialement démontré quand on observa que l'œstradiol peut être lié par le récepteur des androgènes de la prostate (18), avec un $K_{\text {Deq }} \sim 3 \mathrm{nM}$ alors que cette hormone se lie au récepteur des œstrogènes avec un $K_{\text {Deq }} \sim 0,1 \mathrm{nM}$. Comme on a pu observer dans 
des cellules clonées, et donc en principe d'un seul type, la présence simultanée des récepteurs des œstrogènes et des androgènes (76), il vient à l'idée que l'œstradiol peut en quelque sorte choisir entre les deux récepteurs, en suivant la loi d'action de masse, c'est-à-dire en fonction de la constante et de l'affinité des deux protéines de liaison. L'œstradiol ef la dihydrotestostérone peuvent chacun augmenter la croissance des fibroblastes de souris L-929 (en culture depuis 30 ans), et chaque hormone le fait en utilisant son propre récepteur (77). Au niveau d'explants de prostate de rat en culture, l'œstradiol semble exercer un effet antiandrogène en interagissant avec les sites du récepteur des androgènes (78). La liaison des androgènes aux récepteurs de l'œstradiol, bien que difficile à observer à cause de sa faible affinité, est bien démontrée, ei la lestostérone et la dihydrotestostérone à des doses pharmacologiques semblent pouvoir provoquer des effets œstrogéniques (79). C'est également le cas pour des métabolites habituellement négligés tel que $3 \beta$-androstanediol ( $P$. Robel ef J. Hochman, 1976, non publié). L'interprétation de la superposition de la distribution des récepteurs des androgènes et des œstrogènes observés par autoradiographie à différents niveaux du cerveau $(80,81)$ est donc difficile à cause des liaisons communes aux deux récepteurs et, de plus, la conversion locale des androgènes en œstrogènes (82) peut encore compliquer la signification des résultats.

La progestérone fournit un autre exemple d'ambiguïté de liaison car, en plus de son propre récepteur, elle se lie aussi à ceux des androgènes, des glucocorticostéroïdes et des minéralocorticostéroïdes (67). La progestérone est un androgène faible au niveau des cellules prostatiques (et d'ailleurs l'acétate de cyprotérone, un anti-androgène efficace, est un dérivé de la progestérone) ; elle est anti-glucocorticostéroïde dans les cellules d'hépatome et les cellules lymphoïdes, et finalement elle est antiminéralocorticostéroïde au niveau du rein. Ainsi peut-on en conclure qu'une hormone naturelle telle la progestérone peut, dans différentes cellules, être active via différents récepteurs. Elle peut même l'être éventuellement dans les mêmes cellules, ce qui est le cas des MCF-7 obtenues à partir d'un cancer humain, où elle peut interagir non seulement avec les récepteurs de la progestérone mais avec ceux des androgènes et des glucocorticostéroïdes, sans compter un effet direct sur la concentration du récepteur des œstrogènes : il n'y a pas de raison pour que cette situation ne se rencontre pas également au niveau des tumeurs in vivo. Ainsi un stéroïde peut êłre directement actif dans une cellule même en l'absence de son récepteur spécifique, en utilisant donc l'ambiguïté des récepteurs des autres hormones*. Ces considérations théoriques indiquent la difficulté qu'il peut y avoir à prévoir l'effet thérapeutique d'une médication hormonale donnée en l'absence de la connaissance du récepteur. Si différents récepteurs peuvent lier la même hormone, il s'ensuif que réciproquement un récepteur donné peut lier différentes hormones. L'hormone hétérologue exercera soit un effet agoniste par rapport aux stéroïdes spécifiques du récepteur, ou bien exercera une activité différente, par exemple antagoniste ; les propriétés de liaison à elles seules ne permettent pas de prédire quel type d'activité sera obtenu.

* Que l'hormone puisse être indirectement active sur des cellules qui ne possèdent pas de récepteurs est tout à fait évident quand on considère le système endocrinien dans son intégralité : par exemple, les stéroïdes sexuels peuvent êfre actifs indirectement sur de nombreuses cellules ou organes en influençant la sécrétion des hormones hypophysaires. 
Les notions précédentes sont naturellement applicables aux métabolites des hormones et à des analogues de synthèse.

Méfabolites hormonaux. Au niveau de la prostate ventrale de rat, l'androstanolone ou dihydrotestostérone formée dans ce tissu par la $5 \alpha$-réductase à partir de la testostérone, est plus active que celle-ci (84), et elle est liée préférentiellement par le récepteur des androgènes $(85,86)$. Dans les muscles, qu'il s'agisse du releveur de l'anus ou de muscles squelettiques périphériques $(87,87$ bis), la testostérone est le ligand naturel du récepteur des androgènes. Celui-ci est le même dans tous les organes, mais il semble qu'une interaction d'affinité plus élevée soit nécessaire à certains moments du développement, comme l'indique le pseudohermaphrodisme mâle incomplet par déficience génétique de la $5 \alpha$-réductase (88). Dans le système nerveux central, il est très possible que les œstrogènes qui sont des métabolites de la testostérone (82), puissent médier par les récepteurs des œstrogènes certaines fonclions que l'on avait attribuées classiquement à la testostérone elle-même (masculinisation de l'hypothalamus, comportement sexuel), et que la testostérone ou ses métabolites réduits soient impliqués dans le contrôle de gonadotropines par le récepteur des androgènes. Les catécholœstrogènes, formés en abondance dans le cerveau (49) et qui se lient au récepteur de l'œstradiol (90), peuvent également avoir un rôle régulateur particulier (peut-être antagoniste) (91).

Analogues de synthèse. De nombreux analogues de synthèse, stéroïdes ef non stéroïdes sont utilisés en thérapeutique. Le plus connu, le diéthylstilbœstrol (DES), a un effet thérapeutique dans le cancer de la prostate, le premier historiquement reconnu (92). Ce composé est, curieusement, aussi celui qui a provoqué les anomalies du développement et les cancers au niveau du vagin des filles exposées à des doses massives pendant la grossesse de leur mère (93). II est clair que la conformation du DES, analysée par rayons $X$, est compatible avec une interaction avec le récepteur de l'œstradiol (94), confirmant les études biologiques et de liaison. Cependant l'insuffisance des connaissances au niveau des récepteurs ne permet pas de dire que les complexes avec le DES sont identiques aux complexes cstradiol-récepteur et ne puissent pas provoquer un autre effet que ceux déclenchés par l'œstrogène naturel. De plus, et contrairement à l'œstradiol, le DES ne se lie pas au récepteur des androgènes, et on ne peut exclure que cette différence soit importante. On peut presque dire que le diéthylstilbœstrol est plus purement un œstrogène que l'œstradiol lui-même, comme la dexaméthasone est un glucocorticostéroïde plus pur que le cortisol puisqu'il interfère moins avec le récepteur des minéralocorticostéroïdes (95). Des analogues de synthèse peuvent montrer une cinétique de liaison et/ou un métabolisme très différent de celui de l'hormone naturelle. Ces paramètres influencent leurs effets, et par exemple la possibilité de jouer un rôle agoniste ou antagoniste, puisque la survenue de l'importance d'une réponse est liée à la durée pendant laquelle les complexes ligand-récepleur séjournent dans les noyaux cellulaires. Certains composés de synthèse peuvent, du fait de leur spécificité de liaison et de leur vitesse de dissociation lente, être utilisés comme marqueur de choix pour les récepteurs (96) et dans certains cas ils peuvent aussi être des agents thérapeutiques particulièrement intéressants parce que très sélectifs.

La liaison différentielle des hormones et des analogues à un site donné peut s'appliquer également aux protéines du plasma. En conséquence, celles-ci peuvent 
influencer différemment la disponibilité des stéroïdes naturels à leur récepteur. Inversement les stéroïdes de synthèse qui se lient peu aux protéines du plasma, acquièrent de ce fait un pouvoir plus élevé, ce qui est le cas du DES et du $11 \beta$-methoxy-17 $\alpha-$ ethynyl-œstradiol (R 2858) qui se lie peu à la SBP (Sex Steroid Binding Plasma Protein), du R 5020 qui est un analogue de la progestérone et de le dexaméthasone qui se lie peu à la transcortine, etc... (19). Enfin, et bien que la question soit encore peu étudiée, la distribution différentielle des protéines du plasma dans les tissus pourrait être également importante pour expliquer certaines différences dans la concentration et dans l'activité des différentes hormones naturelles et synthétiques (par exemple la corticostérone, la dexaméthasone dans différentes régions cérébrales) (81).

\section{Changement de la concentration des récepteurs.}

L'exemple de l'effet de l'œstradiol sur la concentration des récepteurs de la progestérone, cité plus haut, indique bien la signification pharmacologique précise du phénomène. Un exemple récent, celui du cancer de l'endomètre qui est sensible au traitement par les progestagènes, a été étudié récemment (68). On sait que le traitement devient inefficace après un certain temps, sans que l'on puisse dire si la chose est liée à l'effet des composés progestagènes eux-mêmes qui, on le sait, « inactivent» le récepteur de la progestérone (50). Il est donc intéressant de noter que le tamoxifen, un anti-œstrogène de la série triphényléthylène, peut augmenter significativement la concentration de récepteur de la progestérone dans les tissus cancéreux après administration de quelques jours, alors qu'il ne se révèle pas œstrogène si l'on observe en particulier son effet sur certains paramètres impliqués dans la division cellulaire (68). On a pu observer d'autre part, l'inhibition sélective de la concentration des récepteurs des œstrogènes de cellules $L$ en présence d'androgènes (77). On ne sait pas encore si la concentration des récepteurs des hormones stéroïdes pourra être sélectivement modulée par des composés non stéroïdes et non hormonaux; on a rapporté que la perphénazine diminue la concentration des récepteurs de l'œstradiol dans le cerveau (97).

\section{Anti-hormones.}

Les principes que nous appliquons aux hormones s'appliquent également aux anti-hormones c'est-à-dire aux composés qui s'opposent à l'effet hormonal au niveau des cellules cibles. Nous envisageons également ici deux mécanismes.

II est logique de penser que la diminution de la concentration du récepteur doit diminuer l'activité hormonale. Sur cette base, et considérant que la progestérone « inactive » son propre récepteur, nous avons proposé une méthode de contraception au milieu du cycle (« mid cycle » contraception), pour laquelle un ligand ayant peu ou pas d'activité progestative inactiverait prématurément le récepteur de la progestérone qui est naturellement augmenté à cette période du cycle (98). Il est clair que prospectivement, on souhaite disposer de médicaments capables de faire décroître sélectivement la concentration des récepteurs hormonaux.

Pour le temps présent, on doit cependant envisager plus simplement des antihormones qui montrent des propriétés de liaison compétitives au niveau du site liant l'hormone à laquelle ils s'opposent. L'antagoniste idéal serait celui qui se lierait avec assez d'affinité pour exclure efficacement l'hormone, un métabolisme suffisamment 
lent pour rester disponible pendant longtemps, et une structure telle que son interaction avec le récepteur soit non seulement spécifique de celui-ci mais également sans effet agoniste. En d'autres termes, on souhaite une anti-hormone « pure » ef de grande activité. Le tamoxifen a récemment démontré dans le système d'oviducte de poule, des propriétés antagonistes puissantes, sans pour autant que se développe quand on l'injecte seul d'effet œstrogène (99). Ainsi a-t-il les caractéristiques que nous souhaitons et en tout cas il sert à l'étude du mécanisme d'action des hormones avec une grande efficacité (M. G. Catelli, J. Mester, M. C. Lebeau ef al., non publié). Des observations préliminaires indiquent que son taux d'association avec le récepteur est relativement lent et que son taux de dissociation est rapide ( $D$. Seeley et $C$. Geynet, non publié). Son métabolisme très lent est certainement responsable de sa disponibilité prolongée au niveau des cellules cibles. Après liaison au récepteur, l'« activation » prend place dans la mesure où l'on observe le transfert du complexe tamoxifen-récepteur dans le noyau, où il séjourne pendant longtemps sans qu'une activité de type œstrogène s'ensuive. Dix mg de tamoxifen abolissent l'effet d'1 mg d'cestradiol (cette dose est d'ailleurs ellemême élevée, «pharmacologique », et difficile à contrecarrer). Le tamoxifen, quand on le donne après que l'œstrogène aif été administré, arrête rapidement l'effet hormonal (100), et inversement l'œstradiol donné à un animal qui reçoit du tamoxifen peut faire redémarrer les effets œstrogènes si la dose est convenable ( $E$. Muvihill et $M$. G. Catelli, non publié). Plusieurs conclusions importantes semblent possibles à partir de ces observations. La première est que l'activité hormonale ou anti-hormonale ne dépend pas de façon critique de la concentration des récepteurs dans le cytoplasme, puisque le tamoxifen et l'œstradiol sont actifs même dans des conditions sous lesquelles le récepteur cytoplasmique est bas et la plupart des récepteurs localisés dans les noyaux cellulaires. La seconde est que le récepteur cytoplasmique n'est pas nécessairement impliqué dans l'entrée d'un ligand dans le noyau, qu'il s'agisse d'œstradiol ou de tamoxifen, puisque l'un ou l'autre peuvent aborder les sites du récepteur après un passage trans-cytoplasmique sans liaison. Au contraire, les résultats suggèrent que le récepteur est fondamental pour « interpréter » la structure moléculaire du ligand, car les complexes œstradiol-récepteur sont actifs et tout se passe comme si les complexes tamoxifen-récepteur ne l'étaient pas (il n'y a pas d'activité œstrogène), alors que le problème du transport intracellulaire de l'hormone semble secondaire.

On peut se demander pourquoi on avait adopté l'hypothèse que l'effet antihormonal était lié à la baisse de concentration des récepteurs cytoplasmiques (101) ? Pour l'essentiel, parce que l'anti-hormone bloque la resynthèse du récepteur de l'œstradiol qui dépend elle-même de l'effet œstrogène. Cependant, avec le système aviaire, le simple fait que le tamoxifen est antagoniste quand on injecte au même moment que l'œstradiol, indique bien que l'activité anti-hormonale n'est pas médiée par la baisse du récepteur cytoplasmique. Cependant la décroissance du récepteur cytoplasmique peut avoir secondairement un effet antihormonal propre, que nous avons d'ailleurs discuté plus haut. En fait et par conséquent, l'hypothèse la plus simple est que le tamoxifen est un ligand allostérique du récepteur lui donnant une conformation anormale qui ne permet pas l'effet œstrogène. Il s'ensuit d'ailleurs que la notion d'« accepteur » responsable de la liaison nucléaire du récepteur «activé » n'aide pas beaucoup pour distinguer les activités hormonales et anti-hormonales.

Le tamoxifen nous a procuré un exemple assez simple d'effet anti-hormonal au 
niveau de l'oviducte de poule en abolissant complètement l'effet œstrogène (99). Cependant plus récemment, des observations inattendues faites au cours de l'administration conjointe de tamoxifen et de progestérone ont indiqué qu'il n'était pas exclu que le tamoxifen ne soit pas seulement un anti-œstrogène $(M . G$. Catelli, N. Binart et $M$. Govezou, non publié). De plus les effets du tamoxifen sont très difficiles à comprendre dans d'autres systèmes biologiques, comme par exemple au niveau de l'utérus de rał ou, comme d'autres analogues dérivés du triphényléthylène, il est non seulement anti-œstrogène mais également œstrogène (102). Nous avons vu que dans le cancer de l'endomètre, il se comporte comme un œstrogène « partiel », augmentant la concentration du récepteur de la progestérone comme un œstrogène sans pour autant, en première approximation, avoir des effets sur la croissance cellulaire (68). Au niveau du système nerveux central, chez le rat, une anti-hormone voisine (la nafoxidine) est anti-œstrogène pour un test de comportement (lordose) et au contraire œstrogène pour un autre (appétit) (103).

II est certain que l'étude détaillée des interactions ligand-récepteur-structure(s) effecteur(s) restera difficile à étudier pendant encore longtemps. Cependant dès à présent l'étude de la distribution du ligand au niveau des cibles ef les paramètres cinétiques de sa liaison peuvent aider à le définir comme composé thérapeutique potentiel. On sait que des agonistes « faibles », d'affinité basse du fait de leur vitesse de dissociation rapide, peuvent avoir des effets anti-hormonaux quand ils sont administrés en même temps que l'agoniste. Pourtant leur administration répétée conduira à une activité pleinement agoniste, comme le démontre le cas de l'œstriol (104). Ainsi, en choisissant de façon appropriée les doses et le rythme de l'administration, on peut obtenir une activité hormonale ou anti-hormonale qui sera la résultante complexe des propriétés dynamiques de liaison, des caractéristiques métaboliques, et/ou des changements de conformation du récepteur.

Ainsi, un certain nombre de mécanismes de base impliqués dans les effets hormonaux et anti-hormonaux sont donc connus. Cela ne signifie pas qu'ils soient faciles à appliquer pour mettre au point de nouveaux médicaments. On utilise déjà les méthodes de liaison comme test de «screening » initial des médicaments.

\section{V. - Interaction des stéroïdes à la surface des cellules cibles. Le cas de la division méiotique de l'œuf des Xenopus laevis et sa signification possible.}

Nous nous sommes intéressé récemment à la reprise de la méiose dans les ovocyłes de Xenopus laevis, qui peut s'obtenir in vitro si on ajoute de la progestérone au milieu de culture (105-107). Les effets que l'on observe sont la rupture de la vésicule germinale (noyau) (GVBD : Germinal Vesicle Break-Down) et une augmentation de la synthèse de protéines spécifiques. La micro-injection de progestérone à l'intérieur des ovocytes ne provoque pas la réponse. Au contraire celle-ci peut survenir si on incube, des ovocytes énucléés, ef l'on peut même prélever le MPF (maturation promoting factor), le transférer dans un ovocyte non traité et y provoquer la GVBD ainsi que les changements des synthèses protéiques. Ainsi les effets de la progestérone dans ce système apparaissent ne dépendre ni d'un événement nucléaire (transcriptionnel) ni d'un 
récepteur intracellulaire, d'autant qu'on ne peut détecter une liaison spécifique dans le cytoplasme.

La progestérone et de nombreux autres stéroïdes (tabl. 1) sont actifs à des concentrations variant de $10 \mathrm{nM}$ à $1 \mu \mathrm{M}$, par conséquent plus élevées que celles correspondant au $K_{\text {Deq }}$ des récepteurs intracellulaires des cellules somatiques des mammifères auxquels nous nous sommes référés jusqu'ici. La diversité stéréochimique des stéroïdes actifs est très différente de la spécificité des interactions stéroïde-récepteur intracellulaires que nous avons étudiées plus haut, mais de l'affınité relativement faible et de cette spécificité relativement lâche, il ne fauł pas conclure pour autant qu'il n'y a pas sélectivité. En effet, nous avons pu montrer que des stéroïdes suffisamment voisins chimiquement pour ne pas avoir de propriétés de solubilité très différentes, ne montraient pas d'effets similaires à ceux de la progestérone. Parmi ceux-ci, certains ont pu être opposés à la progestérone ef montrer un effet antagoniste, tels les œstrogènes, alors que d'autres, plus éloignés structuralement et non agonistes, tels des stérols, ne se sontmontré ni agonistes, ni antagonistes. De ces résultats, nous avons conclu qu'il y avait un site au niveau des ovocytes dont la spécificité de liaison était différente de celle des récepteurs (100). Sa structure pourrait comporter des lipides. Des expériences récentes (108) ont suggéré que l'interaction décisive de la progestérone avec l'ovocyte se situe à la surface de la cellule. En effet, un analogue de la progestérone (androsta-4ene-3-one-17 $\beta$-carboxyacid) a été lié à un polymère soluble (amino-propyl-polyethylene-oxide de poids moléculaire 20000) et le complexe n'entre pas dans les ovocytes.

\section{TABLEAU 1}

Stéroïdes actifs pour réinitier la méiose dans les œufs de Xenopus Laevis in vitro (107)

\begin{tabular}{|c|c|}
\hline \multicolumn{2}{|c|}{ Agonistes } \\
\hline $\begin{array}{l}\text { Progestérone } \\
\text { R } 5020\end{array}$ & $\begin{array}{l}\text { L'hormone naturelle ef la plus active. } \\
\text { Un progestagène synthétique. }\end{array}$ \\
\hline Déoxycorticostérone, Cortisol, Testostérone & $\begin{array}{l}\text { Hormones naturelles mais qui n'ont pas de rapport } \\
\text { physiologique avec la maturation. }\end{array}$ \\
\hline $\begin{array}{l}\text { 19-Nortestostérone } \\
\text { Prégnénolone }{ }^{+}, \text {Androstènédione }++\end{array}$ & $\begin{array}{l}\text { Un androgène synthétique. } \\
\text { Pré-hormones qui sont métabolisées en proges- } \\
\text { térone }{ }^{+} \text {ou testostérone }{ }^{++} \text {. }\end{array}$ \\
\hline $\begin{array}{l}5 \alpha \text { ou } \beta \text {-Dihydroprogestérone } \\
5 \alpha \text { ou } \beta \text {-Dihydrotestostérone }\end{array}$ & $\begin{array}{l}\text { Métabolites qui ne sont pas métabolisés pour } \\
\text { redonner leur hormone respective. }\end{array}$ \\
\hline \multicolumn{2}{|c|}{$\begin{array}{c}\text { Antagonisfes } \\
\text { (avec peu ou pas d'effet agoniste) }\end{array}$} \\
\hline $\begin{array}{l}\text { 16 } \alpha \text {-Méthyl-, ou Ethyl-, ou Ethynyl-19-Nor- } \\
\text { testostérone }\end{array}$ & Dérivés synthétiques de la série 19-nortestostérone. \\
\hline Oestradiol, 8-Iso-œstradiol & Oestrogènes naturel et synthétique. \\
\hline \multicolumn{2}{|c|}{ Ni agoniste ni antagoniste } \\
\hline $\begin{array}{l}\text { 13ß-Propyl-Cortisol, R } 2323 \\
\text { Diéthylstilbœstrol } \\
\text { Cholestérol, Déoxycholic acide }\end{array}$ & $\begin{array}{l}\text { Dérivés synthétiques avec } 2 C \text { ou } 3 C-13 \beta \text { chaîne } \\
\text { latérale. } \\
\text { Oestrogène synthétique non stéroïde. } \\
\text { Composés en } C 27 \text { et } C 25 \text {. }\end{array}$ \\
\hline
\end{tabular}


Cependant il est capable de provoquer la méiose. Des contrôles ont été opérés avec des dérivés radioactifs ef l'activité biologique ne peut, en conséquence, pas être attribuée à l'entrée dans l'ovocyte du matériel hormonal complet ou partiellement coupé. D'autres expériences ont d'ailleurs indiqué qu'on pouvait déclencher la méiose au niveau de la membrane. En particulier, en utilisant de nombreuses drogues telles que des inhibiteurs $\beta$-adrénergiques, des anesthésiques locaux, efc... à des concentrations millimolaires. M. Schorderet et S. Schorderet-Slatkine ont pu reproduire l'effet de la progestérone, par un mécanisme probablement proche de ce que l'on appelle l'effet stabilisant de membrane, ou l'activité d'anesthésie locale. De toute façon une corrélation a pu être faite entre la liste des composés actifs et leur propriété de déplacer des ions $\mathrm{Ca}^{++}$liés à la membrane et/ou de changer la distribution cellulaire de $\mathrm{Ca}^{++}$dans de nombreux systèmes le plus souvent utilisés par des pharmacologistes. La maturation méiotique peut être également provoquée par l'ionophore $23187 \mathrm{(si} \mathrm{Ca}^{++}$ou $\mathrm{Mg}^{++}$ sont présents) ou par une iontophorèse sélective d'ions $\mathrm{Ca}^{++}$, ou par exposition au lanthanum, alors que à l'inverse l'effet de la progestérone peut être aboli si les ovocytes ont été injectés préalablement avec de l'EGTA (revue in 107). Ces faits suggèrent par conséquent que les ions calcium pourraient être impliqués comme deuxième messager après que le signal stéroïde soit intervenu au niveau membranaire. Nous avons d'ailleurs de plus récemment observé que la progestérone peut diminuer l'accumulation de c-AMP provoquée par la toxine cholérique dans les ovocytes (109), ce qui pourrait être une conséquence de la modification calcique.

Nous nous sommes ensuite demandé si le mécanisme d'interaction au niveau de la membrane était propre à l'ovocyte d'amphibien. En fait, un mécanisme analogue semble opérer dans d'autres espèces, en particulier des poissons. Inversement, par exemple au niveau du foie des amphibiens, la vitellogenèse se fait sous l'influence de l'œstradiol médié par un récepteur intracellulaire. II semble en fait que le véritable problème est de savoir si les stéroïdes peuvent agir au niveau de la membrane de cellules cibles somatiques. On peut remarquer que dans le cas de l'ovocyte d'amphibien, l'hormone active, la progestérone, est produite par les cellules folliculaires qui entourent la cellule-cible établissant localement une concentration élevée du stéroïde, la faible affinité apparente de l'interaction observée dans les expériences in vitro étant logiquement bien adaptée à cette situation. Cette distribution «locale » de l'hormone s'oppose à la diffusion générale réalisée par le système vasculaire au niveau de la plupart des organes périphériques. Par contre une situation semblable pourrait être le fait de la testostérone produite par les cellules de Leydig et accédant directement aux tubes séminifères dans les testicules, ou aux glucocorticostéroïdes corticosurrénaliens atteignant les cellules de la médullo-surrénale. Une autre possibilité, plus hypothétique mais fonctionnellement intéressante, serait qu'au niveau de certaines cellules du système nerveux central, la synthèse d'œstrogènes ò parlir des androgènes crée dans un micro-environnement une concentration élevée suffisante pour être compatible avec un $\mathrm{K}_{\text {Deq }}$ de l'ordre de $10^{-7} \mathrm{M}$. Cependant rien n'oblige à penser que tous les systèmes en rapport avec les interactions membranaires auront des caractéristiques physicochimiques identiques à celles observées au niveau de l'ovocyte. Une autre caractéristique attendue d'une interaction de surface de l'hormone est de pouvoir déclencher très rapidement une réponse, dans des délais de l'ordre de la seconde, qui sont plus brefs que ceux attendus d'une modulation au niveau des gènes. A cel égard les réponses 
électriques observées au niveau des cellules hypothalamiques à la suite d'administration de stéroïdes semblent pouvoir être intéressantes à étudier. C'est pourquoi on a récemment synthétisé des stéroïdes avec une copule acide qui défavorise leur entrée dans les cellules, et de fait avec l'œstradiol-7 $\alpha$-bulyrique une série d'expériences de contrôle indique qu'il n'agit plus comme un œstrogène dans la mesure où il n'a pas d'activité dans une série de systèmes classiques où l'œstradiol est actif. Pourtant, introduit par électrophorèse au niveau de cellules cérébrales, il provoque des modifications de l'activité électrique (127). Les résultats obtenus ont indiqué qu'un nombre restreint de cellules sont sensibles à ce dérivé de l'œstradiol, et que par-delà cette spécificité cellulaire il y a également une spécificité stéroïdienne dans la mesure où des dérivés acides d'autres hormones stéroïdes ont montré une efficacité différente entre elles et avec l'œstradiol-7 $\alpha$-butyrique. Les résultats obtenus sont compatibles avec des effets sélectifs à la surface des cellules testées sans qu'on puisse actuellement indiquer leur signification physiologique. Dans plusieurs domaines, l'effet des stérö̈des est resté mal expliqué. II ne s'agit pas seulement des activités cérébrales, mais également un mécanisme par lequel certains sont anesthésiques (111), ou de celui par lequel les glucocorticostéroïdes sont anti-inflammatoires. En tout cas, ce n'est pas la première fois que l'on parle de l'effet des hormones stéroïdes à la surface des cellules : plusieurs théories ont éfé avancées sur la base de travaux avec des membranes lipidiques artificielles (123, $124,125,126)$, des interactions spécifiques de l'œstradiol ont été décrites au niveau de la surface des cellules utérines (110) €t on a évoqué une interaction spécifique au moment de l'entrée du stéroïde dans les cellules utérines (112). Parmi les conséquences d'une interaction membranaire, un changement rapide de perméabilité et/ou de polarisation de membrane apparaît comme une des possibilités très plausibles, et si on en reste à des hypothèses relativement vagues, on sait que les modifications au niveau membranaire sont impliquées d'une façon ou d'une autre dans les processus menant à la division cellulaire et à la différenciation, dont les hormones stéroïdes sont les protagonistes dans un certain nombre de cas.

Le fait que nous ayions décrit pour la première fois de façon détaillée l'activité des hormones stéroïdes au niveau de la surface d'une cellule cible el qu'elle n'implique pas un changement de fonctionnement nucléaire, ne s'oppose en rien au fait que les hormones stéroïdes dans la plupart des cellules cibles somatiques agissent de façon décisive dans l'interaction avec un récepteur intracellulaire en provoquant une modification de la transcription $(34,35,57,95)$. De toute façon l'interaction de l'hormone à un autre niveau cellulaire que le noyau pourrait être complémentaire de l'effet nucléaire (ef ceci pourrait être actuellement le cas par exemple dans l'effet précoce des androgènes sur un facteur d'initiation au cours de la synthèse des protéines (113)). Que l'hormone puisse avoir plusieurs niveaux différents d'activité et par conséquent plusieurs mécanismes d'action dans une cellule qui lui répond ne semble pas du tout impossible. D'ailleurs, et de façon presque réciproque, il est intéressant de noter qu'actuellement, à la suite de la démonstration de l'internalisation de certaines hormones polypeptidiques, la question de leur activité intracellulaire est étudiée par plusieurs laboratoires, ce qui n'exclut pas les effets se passant au niveau des récepteurs de surface. 


\section{VI. - Conclusions.}

L'existence de récepteurs intracellulaires spécifiques des hormones stéroïdes dans les cellules cibles somatiques ef le rôle de ces récepteurs pour médier l'action hormonale en provoquani des modifications de la transcription des gènes semblent maintenant bien établis. Les études au niveau moléculaire bénéficieront maintenant des progrès de la purification des récepteurs et des méthodes permises par les anticorps spécifiques correspondants. Par-delà l'étude de la structure des récepteurs, on voudrait en savoir plus sur leur fonctionnement et les progrès se feront en étroite relation avec ceux permettant une meilleure compréhension du fonctionnement des gènes et de la chromatine.

La constatation que plusieurs hormones puissent se lier à un récepteur donné et que plusieurs récepteurs puissent interagir avec la même hormone, que plusieurs récepteurs puissent être présents dans une même cellule et que les conformations de récepteur varient selon les conditions, a mené à une nouvelle approche, en quelque sorte «physiologique», de la pharmacologie. Elle est déjà utilisée pour obtenir de nouveaux agonistes et antagonistes (anti-hormones), et de nouveaux progrès sur les plans diagnostique, pronostique et thérapeutique sont en vue.

Les observations récentes indiquant que les hormones stéroïdes peuvent agir au niveau de la surface cellulaire des ovocytes et provoquer des changements métaboliques sans intervention nucléaire, ouvrent un nouveau domaine d'éfudes. Des résultats préliminaires ont été obtenus au niveau de cellules dy système nerveux central qui semblent compatibles avec ce concept, même s'il reste à en établir la signification physiologique. Au plan cellulaire, on ne peut savoir encore si les deux mécanismes, génétique ef de surface, peuvent exister simultanément au niveau d'une même cellule ou s'ils sont exclusifs l'un de l'autre. Ainsi, le domaine de l'étude des interactions entre les hormones stéroïdes et les cellules cibles est loin d'être épuisé, et il semble même que notre champ de vision puisse s'étendre encore. Les observations à faire dans les quelques années qui viennent seront probablement importantes aussi bien pour l'endocrinologie et la pharmacologie que pour la biologie cellulaire.

Présenté au Colloque D. G. R. S. T. de Port Bail, 27 février-1 er mars 1979.

Accepté en septembre 1979.

Remerciements. - A l'aide du CNRS, de la DGRST, de la Fondation Ford, de l'OMS, de Roussel UCLAF s'est ajouté le support institutionnel de l'INSERM pour permettre ce travail. D'autre part, Heather Mullis, Eileen Muvihill, Françoise Boussac ef Anne Atger m'ont aidé à établir le manuscrit. De plus je remercie tous mes collaborateurs, ef en particulier ceux dont les noms apparaissent au niveau des références citées.

\section{Références}

1. JENSEN E. V., JACOBSON H. I., 1962. Basic guides to the mechanism of estrogen action. Rec. Progr. Hormone Res., 18, 387.414.

2. BAULIEU E. E., ALBERGA A., JUNG I., 1967. Récepteurs hormonaux. Liaison spécifique de l'œstradiol à des protéines utérines. C. R. Acad. Sci. Paris, 265, 354-357. 
3. TOFT D., SHYAMALA G., GORSKI J., 1967. A receptor molecule for estrogens : studies using a cell free system. Proc. nat. Acad. Sci. USA, 57, 1740-1743.

4. TOFT D., GORSKI J., 1966. A receptor molecule for estrogens : isolation from the rat uterus and preliminary characterization. Proc. nat. Acad. Sci. USA, 55, 1574-1581.

5. MILGROM E., BAULIEU E. E., 1969. A method for studying binding proteins, based upon differential dissociation of small ligand. Biochim. biophys. Acta, 194, 602-605.

6. BEST-BELPOMME M., FRIES J., ERDOS T., 1970. Interactions entre l'œstradiol ef des sifes récepteurs uiérins. Données cinétiques de l'équilibre. Eur. J. Biochem., 17, 425-432.

7. TRUONG H., BAULIEU E. E., 1971. Interaction of uterus cyiosol receptor with estradiol equilibrium and kinetic studies. Biochim. biophys. Acta, 237, 167-172.

8. BAULIEU E. E., 1973. A 1972 survey of the mode of action of steroid hormones, 30-62. In, SCOW, Endocrinology, Int. Congr. Ser. no 273, Excerpta med. Amsterdam.

9. MERCIER-BODARD C., ALFSEN A., BAULIEU E. E., 1970. Sex Steroid Binding Plasma Protein. Acta endocrinol., suppl. 147, 64, 204-224.

10. RAYNAUD J. P., MERCIER-BODARD C., BAULIEU E. E., 1971. Rat estradiol binding plasma protein. Steroids, 18, 767-788.

11. FOX L. L., REDEUILH G., BASKEVITCH P., BAULIEU E. E., RICHARD-FOY H., 1976. Production and detection of antibodies against the estrogen receptor from calf uterine cytosol. Febs Leffers, 63, 71-76.

12. RADANYI C., MERCIER-BODARD C., SECCO-MILLET C., BAULIEU E. E., Richard-Foy H., 1977. Alpha-fœtoprotein is not a subunit of the estradiol receptor of the rat uterus (rat alpha-fœetoprotein/estrogen receptors). Proc. nat. Acad. Sci. USA, 74, 2269-2272.

13. RENOIR J. M., FOX L. L., BAULIEU E. E., MERCIER-BODARD C., 1977. An antiserum specific for human sex steroid binding plasma protein. Febs Letters, 75, 83-88.

14. GREENE G. L., CLOSS L. E., FLEMING H., DE SOMBRE E. R., JENSEN E. V., 1977. Antibodies to estrogen receptor : immunochemical similarity of ostrophilin from various mammalian species. Proc. nat. Acad. Sci. USA, 74, 3681-3685.

15. RADANYI C., REDEUILH G., EIGENMANN E., LEBEAU M. C., MASSOL N., SECCO C., BAULIEU E. E., RICHARD-FOY H., 1979. Production ef détection d'anticorps anti-récepteur de I'œstradiol d'utérus de veau. Interaction avec le récepteur d'oviducte de poule. C. R. Acad. Sci. Paris, Sér. D., 288, 255-258.

16. FANG S., ANDERSON K. M., LIAO S., 1969. Receptor protein for androgens. On the role of specific proteins in selective retention of 17ß-hydroxy- $5 \alpha$-androstan-3-one by rat ventral prostate. J. biol. Chem., 244, 6584-6595.

17. MAINWARING W. I. P., 1969. A soluble androgen receptor in the cytoplasm of rat prostate. J. Endrocrinol., 45, 531-541.

18. BAULIEU E. E., JUNG I., 1970. Prostatic cytosol receptor. Biochem. biophys. Res. Commun., 38, 599-606.

19. MILGROM E., ATGer M., BAULIEU E. E., 1970. Progestérone in uterus and plasma. IV. Progesterone receptor(s) in guinea pig uterus cytosol. Steroids, 16, 741-754.

20. O'MALLEY B. W., TOFT, D. O., SHERMAN M. R., 1970. Progesterone receptors in the cytoplasm and nucleus of chick oviduct target tissue. Proc. nat. Acad. Sci. USA, 67, 501-509.

21. MUNCK A., WIRA C., 1971. Glucocorticoid receptors in rat thymus cells. In RASPÉ G., Adv. Biosci., 7, 301-330. Pergamon Press Viewreg, Oxford.

22. SHARP G. W. G., KOMACK C. L., LEAF A., 1966. Studies on the binding of aldosterone in the Toad Bladder. J. clin. invest., 45, 450-459.

23. SWANECK G. E., CHU L. H., EDELMAN I. S., 1970. Stereo-specific binding of aldosterone to renal chromatin. J. biol. Chem., 245, 5382-5389.

24. LEBEAU M. C., MASSOL N., BAULIEU E. E., 1973. An unsoluble receptor for cestrogens in the " residual » nuclear proteins of chick-liver. Eur. J. Biochem., 36, 294-300.

25. MESTER J., BAULIEU E. E., 1977. Progesterone receptors in the chick oviduct : determination of the fotal concentration of binding sites in the cytosol and nuclear fraction and effect of progesterone on their distribution. Eur. J. Biochem., 72, 405-414.

26. SICA V., NOLA E., PARIKH I., PUCA G. A., CUATRECASAS P., 1973. Purification of œstradiol receptors by affinity chromatography. Nature New Biol., 244, 36-39.

27. KUHN R. W., SCHRADER W. T., SMITH R. G., O'MALLEY B. W., 1975. Progesterone binding 
components of chick oviduct purification by affinity chromatography. J. biol. Chem., 250, $4220-4228$.

28. TRUONG H., GEYNET C., MILLET C., SOULIGNAC O., BUCOURT R., VIGNAU M., TORELLIV., BAULIEU E. E., 1973. Purification of estradiol receptor by affinity chromatography. Representative experiments. Febs Leffers, 35, 289-294.

29. HUBERT P., MESTER J., DELLACHERIE E., NEEL J., BAULIEU E. E., 1978. Soluble biospecific macromolecule for purification of estrogen receptor. Proc. nat. Acad. Sci. USA, 75, 3143-3147.

30. ERDOS T., 1968. Properties of a uterine œstradiol receptor. Biochem. biophys. Res. Commun., 32, 338-343.

31. SHERMAN M. R., PICKERING L. A., R.OLLWAGEN F. M., MILLER L. K., 1978. Mero-receptors : proteolytic fragments of receptors containing the steroid-binding site. Fed. Proceed., 37, $167-$ 173.

32. WRANGE O., GUSTAFSSON J. A., 1978. Separaíion of the hormone- and DiNA-binding sites of the hepatic glucocorticoid receptor by means of proteolysis. J. biol. Chem., 253, 856-865.

33. MUELLER G. C., HERRANEN A. M., JERVELL K. F., 1958. Studies on the mechanism of action of estrogens. Rec. Progr. Hormone Res., 14, 95-140.

34. O'MALLEY B. W., MEANS A. R., 1974. Female steroid hormones and target cell nuclei. Science, 183, 610-620.

35. SCHIMKE R. T., PENNEQUIN P., ROBINS D., MAC KNIGHT G. S., 1977. Hormonal regulation of egg-white protein. In DUMONT J., NUNEZ J., Hormones and cell regulation, Eur. Symp., 1, 209-221. North Holland Publ. Co, Amsterdam.

36. JENSEN E. V., SUZUKI T., KAWASHIMA T., STUMPF W. E., JUNGBLUT P. W., DE SOMBRE E. R. 1968. A two-step mechanism for the interaction of cestradiol with the rat uterus. Proc. nat. Acad. Sci. USA, 59, 632-638.

37. GORSKI J., TOFT D. O., SHYAMALA G., SMITH D., NOTIDES A., 1968. Hormone receptors : studies on the interaction of estrogen with the uterus. Rec. Progr. Hormone Res., 24, 45-72.

38. HIGGINS S. J., ROUSSEAU G. G., BAXTER, J. D., TOMKINS G. M., 1973. Early events in glucocorticoid action activation of steroid receptor and its subsequent specific nuclear binding, studied in a cell free system. J. biol. Chem., 248, 5866-5872.

39. MILGROM E., ATGER M., BAULIEL E. E., 1973. Acidophilic activation of steroid hormone recepiors. Biochemistry, 12, 5198-5205.

40. EDELMAN I. S., BOGOROCH R., PORTER G. A., 1964. On the mechanism of action of alcosterone on sodium transport : the role of protein synthesis. Proc. nat. Acad. Sci. USA, 50, 1169-1176.

41. MASSOL N., LEBEAU M. C., BAULIEU E. E., 1978. Estrogen receptor in hen oviduct chromatin, digested by micrococal nuclease. Nucl. Acids Res., 5, 723-738.

42. SENIOR M. B., FRANKEL F. R., 1978. Evidence for two kinds of chromatin binding sites for estradiol-receptor complex. Cell, 14, 857-863.

43. MESTER J., BAULIEU E. E., 1972. Nuclear estrogen recepior of chick liver. Biochim. Biophys. Acta, 261, 236-244.

44. ZAVA D. T., MAC GUIRE W. L., 1977. Estrogen receptor unoccupied sites in nuclei of a breast tumor cell line. J. biol. Chem., 252, 3703-3708.

45. RAYNAUD-JAMMET C., BAULIEU E. E., 1969. Action de l'cestradiol in vitro : augmentation de la biosynthèse d'ARN dans les noyaux utérins. C. R. Acad. Sci. Paris, 268, 3211-3214.

46. SCHWARTZ R. J., KUHN R. W., BULLER R. E., SCHRADER W. T., O'MALLEY B. W., 1976. Progesterone-binding components of chick oviduct. In vifro effects of purified hormonereceptor complexes on the initiation of RNA synthesis in chromatin. J. biol. Chem., 251, 51665177.

47. RINGOLD G. M., YAMAMOTO K. R., BISHOP J. M., VARMUS H. E., 1977. Glucocorticoidstimulated accumulation of mouse mammary tumor virus RNA : increased rate of synthesis of viral RNA. Proc. nat. Acad. Sci. USA, 74, 2879-2883.

48. MAC KNIGHT G. S., 1978. The induction of ovalbumin and conalbumin mRNA by estrogen and progesterone in chick oviduct explant cultures. Cell, 14, 403-413.

49. PALMITER R. D., MOORE P. B., MULVIHILL E. R., EMTAGE S., 1976. A significant lag in the induction of ovalbumin messenger RNA by steroid hormones : a receptor translocation hypothesis. Cell, 8, 557-572. 
50. MILGROM E., LUU THI M., ATGER M., BAULIEU E. E., 1973. Mechanisms regulating the concentration and the conformation of progesterone receptor(s) in the uterus. J. biol. Chem., 248, 6366-6374.

51. KAHN C. R., 1976. Membrane receptors for hormones and neurotransmitters. .Cell Biol., 70, 261-281.

52. MESTER J., MARTEL D., PSYCHOYOS A., BAULIEU E. E., 1974. Hormonal control of œstrogen receptor in uterus and receptivity for ovoimplantation in the rat. Nature, 250, 776-778.

53. HSUEH A. J., PECK E. J., CLARK J. H., 1975. Progesterone antagonism of the cestrogen receptor and œstrogen-induced uterine growth. Nature, 254, 337-339.

54. TSENG L., GURPIDE E., 1975. Nuclear concentration of estradiol in superfused slices of human endometrium. J. clin. Endocrinol., 41, 402-404.

55. BAYARD F., DAMILANO S., ROBEL P., BAULIEU E. E., 1978. Cyłoplasmic and nuclear estradiol and progesterone receptors in human endometrium. f. clin. Endocrinol. Metab., 46, 635-648.

56. ALBERGA A., BAULIEU E. E., 1965. Concentration élective de l'œstradiol dans l'endomètre chez la ratte. C. R. Acad. Sci. Paris, 261, 5226-5228.

57. JENSEN E. V., DE SOMBRE E. R., 1972. Mechanism of action of the female sex hormones. Ann. Rev. Biochem., 41, 203-230.

58. JOST A., 1961. The role of fatal hormones in prenatal development. Harvey Lect., 55, 201-226. Acad. Press, N. Y.

59. KRATOCHWIL K., SCHWARTZ P., 1976. Tissue interaction in androgen response of embryonic mammary rudiment of mouse : identification of target tissue for testosterone. Proc. nat. Acad. Sci. USA, 73, $4041-4044$.

60. LE GOASCOGNE C., BAULIEU E. E., 1977. Hormonally controlled « nuclear bodies » during the development of the prepuberal rat uterus. Biol. Cell., 30, 195-206.

61. GORSKI J., SARFF M., CLARK J., 1971. The regulation of uterine concentration of estrogen binding protein. In RASPÉ G., Adv. Biosci., 7, 5-20. Pergamon Press Viewveg, Oxford.

62. RAYNAUD J. P., MOGUILEWSKY M., 1976. Ontogenèse des récepteurs des œestrogènes chez le rat, 85-92. In A. SOULAIRAC, J. P. GAUTRAY, J. P. ROUSSEAU, J. COHEN, Système nerveux, activité sexuelle et reproduction, Masson et Cie, Paris.

63. GEHRING U., TOMKINS G. M., OHNO S., 1971. Effect of the androgen insensitivity mutation on a cytoplasm.ic receptor for dihydrotestosterone. Nature New Biol., 232, 106-107.

64. SIBLEY C. H., TOMKINS G. M., 1974. Mechanisms of steroid resistance. Cell, 2, 221-227.

65. BOURGEOIS S., NEWBY R., 1977. Diploid and haploid states of the glucocorticoid receptor gene of mouse lymphoid cell lines. Cell, 11, 423-430.

66. JENSEN E. V., BLOCK G. E., SMITH S., KYSER K., DE SOMBRE E. R., 1971. Estrogen receptors and breast cancer response to adrenalectomy prediction of response in cancer therapy. Nat. Cancer Inst. Monogr., 34, 55-70.

67. MAC GUIRE W. L., RAYNAUD J. P., BAULIEU E. E., 1977. Progress in Cancer Research and Therapy, Progesterone Receptors in Normal and Neoplastic Tissues, Vol. 4. Progesterone Receptors : Introduction and Overview, 1-8. Raven Press, New York.

68. ROBEL P., LÉVY C., WOLFF J. P., NICOLAS J. C., BAULIEU E. E., 1978. Réponse à un antiœestrogène comme critère d'hormone-sensibilité du cancer de l'enaomètre. C. R. Acad. Sci. Paris, Sér. D., 287, 1353-1356.

69. PALMITER R. D., MULVIHILL E. R., MAC KNIGHT G.S., SENEAR A.W., 1977. Regulation of gene expression in the chick oviduct by steroid hormones. Cold Spring Harbor Symp. on Quantit. Biol., Symp. on Chromatin, 42, 639-647.

70. SUTHERLAND R. L., LebeAU M. C., SCHMELK P. H., BAULIEU E. E., 1977. Synergistic and antagonistic effects of progesterone and œstrogen on ostrogen receptor concentration and DNA polymerase activity in chick oviduct. Febs Letters, 79, 253-257.

71. BAULIEU E. E., ALBERGA A., RAYNAUD-JAMMET C., WIRA C. R., 1972. New look at the very early steps of cestrogen action in uterus. Nature New Biol., 236, 236-239.

72. ANDERSON J. N., PECK Jr. E. J., CLARK J. H., 1974. Nuclear receptor estradiol complexe : a requirement for uterotrophic responses. Endocrinology, 95, 174-178.

73. KATZENELLENBOGEN B. S., GORSKI J., 1972. Estrogen action in vitro. Induction of the synthesis of a specific uterine protein. J. biol Chem., 247, 1299-1305. 
74. SUTHERLAND R. L., MESTER J., BAULIEU E. E., 1977. Hormonal regulation of sex steroid hormone receptor concentration and subcellular distribution in chick oviduct. In DUMONT J. NUNEZ J., Hormones and cell regulation, Eur. Symp., 1, 31-48. North Holland Publ. Co, Amsterdam.

75. CROCE C. M., KOPROWSKI H., LITWACK G., 1974. Regulation of the corticosteroid inducibility of tyrosine aminotransferase in interspecific hybrid cells. Nature, 249, 839-841.

76. JUNG-TESTAS I., DESMOND W., BAULIEU E. E., 1976. Two sex steroid receptors in SC-115 mammary tumor cells. Exp. Cell Res., 97, 219-232.

77. JUNG-TESTAS 1., BAULIEU E. E., 1979. Effects of sex steroids and antihormones on growth adhesiveness and receptors of L- 929 cells cultured in serum containing and serum free media. Exp. Cell, Res., 119, 75-85.

78. FEYEL-CABANNES T., SECCHI J., ROBEL P., BAULIEU E. E., 1978. Combined effects of testosterone and estradiol on rat ventral prostate in organ culture. Cancer Res., 38, 4126-4134.

79. ROCHEFORT H., GARCIA M., 1976. Androgens on the estrogen receptor. I. Binding and in vivo nuclear translocation. Steroids, 28, 549-560.

GARCIA M., ROCHEFORT H., 1977. Androgens on the estrogen receptor. II. Nuclear translocation and uterine protein synthesis. Steroids, 29, 111-126.

80. STUMPF W. E., SAR M., 1977. Steroid hormone target cell in the periventricular brain : relationship to peptide hormone producing cells. Fed. Proceed., 36, 1973-1977.

81. MAC EWEN B. S., 1976. Interactions between hormones and nerve tissue. Sci. Amer. 235, 48-58.

82. NAFTOLIN F., RYAN K. J., DAVIES I. J., REDDY V. V., FLORES F., PETRO Z., KUHN M., WHITE R. J., TAKAOKA Y., WOLIN L., 1975. The formation of estrogens by central neuroendocrine tissues. Rec. Progr. Hormone Res., 31, 295-316.

83. HORWITZ K. B., COSTLOW M. E., MAC GUIRE W. L., 1975. A human breast cancer cell, line with estrogen, androgen, progesterone, and glucocorticoid receptors. Steroids, 26, 785795.

84. BAULIEU E. E., LASNITZKI I., ROBEL P., 1968. Metabolism of testosterone and action of metabolites on prostate glands growth in organ culture. Nature, 219, 1155-1156.

85. BRUCHOVSKY N., WILSON J. D., 1968. The conversion of testosterone to $5 \alpha$-androstan-17 $\beta-$ ol-3-one by rat prostate in vivo and in vitro. J. biol. Chem., 243, 2012-2021.

86. ANDERSON K. M., LIAO S., 1968. Selective retention of dihydrotestosterone by prostatic nuclei. Nature, 219, 277-279.

87. JUNG I., BAULIEU E. E., 1972. Testosterone cytosol receptor in the rat levator ani muscle. Noture New Biol., 237, 24-26.

87 bis. MICHEL G., BAULIEU E. E., 1974. Récepteurs cytosoluble des androgènes dans un muscle strié squelettique. C. R. Acad. Sci. Paris, Sér. D., 279, 421-424.

88. IMPERATO-MAC GINLEY J., GUERREO L., GAUTIER T., PETERSON R. E., 1974. Steroid $5 \alpha$-reductase efficiency in man : an inherited form of male pseudohermaphroditism. Sciences, 186, 1213-1215.

89. PAUL S. M., AXELROD J., 1977. Catechol estrogens : presence in drain and endocrine tissues. Science, 197, 657-659.

90. DAVIES I. J., NAFTOLIN F., RYAN K. F., FISHMAN J., SIU J., 1975. The affinity of catechol estrogens for estrogen receptors in the pituitary and anterior hypothalamus of the rat, Endocrinology, 97, 554-557.

91. PAUL S. M., SKOLNICK P., 1977. Catechol œstrogens inhibit œstrogen elicited accumulation of hypothalamic cyclic AMP suggesting role as endogenous anti-œestrogens. Noture, 266, 559-561.

92. HUGGINS C., 1967. Endocrine-induced regression of cancers. Science, 156, 1050-1054.

93. BIBBO M., GILL W. B., AZIZI F., BLOUGH R., FANG V. S., ROSENFIELD R. L., SCHUMACHER G. F., SLEEPER K., SONEK M. G., WIED G. L., 1977. Follow-up study of male and female offspring of DES exposed mothers. Obst. Gynecol., 49, 1-8.

94. HOSPITAL. M., BUSETTA M., BUCOURT R., WEINTRAUB H., BAULIEU E. E., 1972. X-ray crystallography of estrogens and their binding to receptor sites. Mol. Pharmacol., 8, 438-445.

95. BAULIEU E. E., ATGER M., BEST-BELPOMME M., CORVOL P., COURVALIN J. C., MESTER J., MILGROM E., ROBEL P., ROCHEFORT H., DE CATALOGNE D., 1975. Steroid hormone receptors, 649-731. In MUSON P. L., Vitomins and hormones vol. 33. Acad. Press, N. Y. 
96. RAYNAUD J. P., OJASOO T., BOUTON M. M., PHILIBERT D., 1978. Receptor binding as a tool in the development of new bioactif steroids. In ARIENS E. J., Drug Design, vol. 8. Acad. Press $N$. Y. (in press).

97. GINSBURG M., MAC LUSKY N. J., MORRIS I. D., THOMAS P. J., 1977. The specificity of œstrogen receptor in brain, pituitary and uterus. Brit. J. Pharmacol., 59, 397-402.

98. BAULIEU E. E., 1975. Antiprogesterone effect and midcycle (periovulatory) contraception. Eur. J. Obst. Gynecol. Reprod. Biol., 4, 161-166.

99. SUTHERLAND R. L., MESTER J., BAULIEU E. E., 1977. Tamoxifen is a potent " pure " anticestrogen in chick oviduct. Nature, 267, 434-435.

100. MESTER J., GEYNET C., BINART N., BAULIEU E. E., 1977. Retarded administration of an antagonist stops steroid hormones action. Biochem. biophys. Res. Commun., 79, 112-118.

101. CLARK J. H., PECK Jr. E. J., ANDERSON J. N., 1974. Oestrogen receptors and antagonism of steroid hormone action. Nature, 251, 446-448.

102. HARPER M. J. K., WALPOLE A. L., 1967. A new derivative of triphenylethylene : effect on implantation and mode of action in rats. J. Reprod. Fert., 13, 101-119.

103. WADE G. N., BLAUSTEIN S. D., 1978. Effects of an anti-estrogen on neural estradiol binding and on behaviors in female rats. Endocrinology, 102, 245-251.

104. HUGGINS C., JENSEN E. V., 1955. The depression of estrone-induced uterine growth by phenolic estrogens with oxygenated functions at positions 6 or 16 . The impedec estrogens. J. exp. Med., 102, 335-346.

105. SMITH L. D., ECKER R. E., 1970. Regulatory processes in the maturation and early cleavage of amphibian eggs. Curr. Top. dev. Biol., 5, 1-38.

106. MASUI Y., MARKERT C. L., 1971. Cytoplasmic control of nuclear behavior during meiotic maturation of frog oocytes. J. exp. Zool., 177, 129-146.

107. BAULIEU E. E., GODEAU F., SCHORDERET M., SCHORDERET-SLATKINE S., 1978 . Steroid induced meiotic division in Xenopus laevis oocytes : surface and calcium. Nature, 275, 593-598.

108. GODEAU F., SCHORDERET-SLAKTINE S., HUBERT P., BAULIEU E. E. 1978 . Induction of maturation in Xenopus laevis oocyjes by a steroid linked to a polymer. Proc. nat. Acad. Sci. USA, 75, 2353-2357.

109. SCHORDERET-SLATKINE S., SCHORDERET M., BOQUET P., GODEAU F., BAULIEU E. E., 1978. Progesterone-induced meiosis in Xenopus Loevis oocyles : a role for c-AMP at the " maturation-promoting factor " level. Cell, 15, 1269-1275.

110. PIETRAS R. J., SZEGO C. M., 1977. Specific binding sites for cestrogen at the outer surfaces of isolated endometrial cells. Nature, 265, 69-72.

111. HALSEY M. J., MILLAR R. A., SUTTON J. A., 1974. Molecular mechanisms in general anaesthesia, Churchill-Livingstone, London.

112. MILGROM E., ATGER M., BAULIEU E. E., 1973. Studies on estrogen entry into uterine cells and on estradiol-receptor complex attachment to the nucleus. To the entry of estrogen into uterine cells a protein-mediated process ? Biochim. biophys. Acta, 320, 267-283.

113. LIANG T., CASTANEDA E., LIAO S., 1977. Androgen and initiation of protein synthesis in the prostate binding of Met-tRNA ${ }_{l}^{\text {Met }}$ to cytosol initiation factor and ribosomal subunit particles. J. biol. Chem., 252, 5692-5700.

114. WILLIAMS D., GORSKI J., 1972. Kinetic and equilibrium analysis of estradiol in uterus : a model of binding site distribution in uterine cells. Proc. nat. Acod. Sci. USA, 69, 3464-3468.

115. YAMAMOTO K. R., ALBERTS B. M., 1976. Steroid receptors : elements for modulation of eukaryotic transcription. Anal. Rev. Biochem., 45, 721-746.

116. BAULIEU E. E., 1976. Intracellular receptor and hormone antagonists, 51-78. In CLARK J. H., KLEE W., LEVITZKI A., WOLFF J., Hormone and antihormone action at the target cell, Life Sci. Res. Rep., 3, Dahlem Konferenzen, Berlin.

117. BRESCIANI F., NOLA E., SICA V., PUCA G. A., 1973. Early stages in estrogen control of gene expression and its derangement in cancer. Fed. Proceed., 32, 2126-2132.

118. EDELMAN I., 1975. Mechanism of action of steroid hormones. J. Ster. Biochem., 6, 147159.

119. MUNCK A., 1976. General aspects of steroid hormone-receptor interaction, 1-40. In PASQUALINI J. R., Receptors and mechanism of action of sferoid hormones, Part I, Marcel Dekker Inc., New York and Basel. 
120. TERENIUS L., 1970. Two modes of interaction between cestrogen and anti-œstrogen. Acta endocr., 64, 47-58.

121. MUNCK A., 1957. The interfacial activity of steroid hormones and synthetic œestrogens. Biochim. biophys. Acfa, 24, 507-514.

122. HECHTER O., LESTER G., 1960. Cell permeability and hormone action. Rec. Progr. Hormone Res., 16, 139-186.

123. WILLMER E. N., 1961. Steroids and cell surfaces. Biol. Rev., 36, 368-398.

124. WEISSMANN G., SESSA G., WEISSMANN S., 1966. Action of steroids and Triton X-100 on phospholipid/cholesterol structures. Biochem. Phormacol., 15, 1537.

125. LUCY J. A., 1968. Theoretical and experimental models for biological membranes, $233-288$. In CHAPMAN D. Biological membranes, Acad. Press. New York.

126. HEAP R. B., SYMONS A. M., WATKINS J. C., 1971. An interaction between œestradiol and progesterone !n aqueous solutions and in a modal membrane system. Biochim. biophys. Acta, 233, 307-314.

127. CARETTE B., BARRY J., LINKIE D., FERIN M., MESTER J., BAULIEU E. E., 1979. Effets de I' « œstradiol-7 $\alpha$-butyrique » au niveau des cellules hypothalamiques. C. R. Acod. Sci. Paris, Sér. D., 288, 631-634. 